\title{
Modern Slavery Statements and Leading UK Hotel Companies
}

\author{
By Peter Jones ${ }^{*}$ \& Daphne Comfort ${ }^{ \pm}$
}

\begin{abstract}
Modern slavery is an insidious problem in many sectors of the global economy, and it is widely perceived to be commonplace in the hospitality industry. However modern slavery has received little attention in the academic hospitality literature and this paper looks to explore one of the ways in which leading hotel companies in the UK have publicly addressed the issue by reviewing their modern slavery statements. The paper adopts a simple methodological approach to review, and offer some reflections on, the modern slavery statements of seven of the leading hotel companies within the UK. The findings revealed that six interlinked themes, namely corporate commitment; risk areas; due diligence; awareness and training; audit; and performance measures; illustrated the seven companies' approach to tackling modern slavery. The authors also suggested that the hotel companies' approaches to modern slavery were expectational and that there were concerns about the scope of the auditing processes employed by the hotel companies and by the limited public reporting of their attempts to tackle modern slavery as part of their approach to corporate social responsibility.
\end{abstract}

Keywords: modern slavery, modern slavery statements, UK hotel industry, hospitality industry, auditing, corporate social responsibility

\section{Introduction}

Modern Slavery, simply defined as "the severe exploitation of other people for personal or commercial gain" (Anti-Slavery International 2021) is an insidious problem in many sectors of the global economy and it is widely perceived to be commonplace in the hospitality industry. Robinson (2013) for example, claimed that "the labour requirements of hospitality services account for an alarming proportion of the world's estimated human bondage population". More recently, CMS Law (2019) a major international law company, argued that "modern slavery" was "a key issue for the hospitality sector". The Human Trafficking Foundation (2018) suggested that the hospitality industry in the UK "has been recognised as one of high-risk regarding modern slavery". French (2018) claimed that "the UK hospitality sector is one that is susceptible to modern slavery". In 2015, the UK Government passed the Modern Slavery Act designed to tackle the problems of slavery and human trafficking and one of its provisions was for large companies to produce an annual statement, setting out the steps the company had

\footnotetext{
*Associate Professor, School of Business, University of Gloucestershire, UK.

${ }^{ \pm}$Daphne Comfort was a Research Associate in the School of Business at the University of Gloucestershire when this paper was written, but sadly she died on August 5th 2021.
} 
taken to ensure there was no slavery in either its business operations or its supply chain.

More generally, the Human Trafficking Foundation (2018) argued that "with more than one in 10 people working in hospitality around the world, the sector has the opportunity to take a strong stand on modern slavery". However, the issue of modern slavery has received little attention in the academic hospitality literature. With these thoughts in mind, this paper looks explore one of the ways in which leading hotel companies in the UK have publicly addressed this issue by reviewing their modern slavery statements. As such, the paper looks to add to the current literature on modern slavery within the hospitality industry. The paper includes an outline of modern slavery, a literature review, a description of the frame of reference and method of enquiry, an exploratory review of the modern slavery statements developed by some of leading hotel companies in the UK, some reflections on these statements, and a number of conclusions which outline the implications raised by the paper.

\section{Modern Slavery}

Defining slavery, and modern slavery, is a complex issue, though the aim here is simply to appreciate, and illustrate, that complexity rather than to analyse it in detail. Allain and Bales (2012) cited the first formal international definition of slavery signed in 1926, namely, "slavery is the status or condition of a person over whom any or all of the powers attaching to the right of ownership are exercised" (United Nations Office of the High Commissioner Human Rights 2021) but argued "the very term slavery and its contours are contested".

Mende (2019) argued that there "is no single definition of the scope and form of modern slavery", but that "a certain image of modern slavery" can be identified, and "this image can be summarised by three denominators", namely "the control of a person over another", "an involuntary aspect in their relation", and "the element of exploitation". For Manzo (2006) "the constituent elements of modern slavery are identified as control without ownership: violence (or the threat of violence); coercion (loss of freedom and choice); and exploitation (of labour power through unpaid work)". In working towards a definition of modern slavery Landman and Silverman (2019) drew attention to the "Bellagio-Harvard Guidelines on the Legal Parameters of Slavery". Here Landman and Silverman (2019) argued that the guidelines emphasised "the notion of control and the lack of agency for victims of slavery, where different forms of coercion maintain power over individuals and prevent them from leaving the conditions of their enslavement".

Landman and Silverman (2019) argued that "popular understandings of slavery often conjure up images of African slaves brought to the Caribbean, Brazil and the US, where such images typically include slave ships, slaves bound in chains and slaves auctioned at market", but that "such imagery tends to obscure current realities of slavery and relegate it as a problem of the past". Further, 
Landman and Silverman (2019) argued that "slavery is alive and well and that it has taken on new forms or updated old forms, comprising a variety of practices that include debt bondage, domestic servitude, forced prostitution, forced labour, forced marriage and human trafficking". Debt bondage, for example, perhaps the most widespread form of modern slavery, occurs where people trapped in poverty borrow money, and are forced into work to pay off the debt, and in so doing, lose control over their employment conditions, and the original debt. Human trafficking, involves the use of violence, threats, or coercion to transport, and often to recruit or harbour people, for labour, forced prostitution or marriage.

Bannerjee (2020) suggested that while slavery is a crime under international law, it remains "a viable and profitable management practice for business", and that "modern slavery, far from being an aberration, is a logical outcome of the way our political economic system is organized and its historical origins in the colonial system". Conservative estimates put the number of victims of modern slavery at over 40 million (International Labour Office 2017), with the annual profits from modern slavery estimated to be some US\$ 150 billion (International Labour Office 2014). Within the UK, Bales et al. (2015) estimated there to be between 10,000 and 13,000 potential victims of modern slavery, but this figure does not include victims of modern slavery in UK companies ${ }^{\text {ee }}$ supply chains in other countries.

In many ways modern slavery often effectively goes unseen in that many of the people working in slavery are in companies se supply chains, while those in customer facing operations might look very much the same as many of their fellow workers. That said, Unseen (2021), a charity working "towards a world without slavery", identified some indicative signs of modern slavery and human trafficking. Namely, individuals who show signs of physical or psychological abuse, look malnourished, unkempt, anxious or agitated, or appear withdrawn or neglected. Their living conditions might be dirty, cramped and overcrowded and they might always wear the same clothes, have few personal possessions, and no identification documents. Further, they might be dropped off at, and collected from, their place of work, early in the morning and late at night, and they may be reluctant to seek help from fellow workers, and be very wary of law enforcement officers and agencies.

Modern slavery is an issue for the hospitality industry worldwide, and the workforce in the hotel sector often consists of people vulnerable to exploitation including migrants, women, and low skilled and low paid workers. More specifically, French (2018) argued that the UK hospitality industry 'e susceptibility to modern slavery, "is reflected in the structure and geography of the sector; its labour intensity and the importance of pay costs; weak unionisation and the lack of formal human resource management; and comparatively high levels of migrant employment". That said, in 2015 the UK Government introduced the Modern Slavery Act, with the obligation for large businesses, more specifically those businesses with an annual turnover in excess of $£ 36$ million, to produce an annual modern slavery statement, with a view to encouraging businesses to tackle issues of forced labour and human trafficking within their businesses and supply chains. 


\section{Literature Review}

To date, modern slavery in the hospitality industry has attracted little attention in the academic literature. In part, this may reflect a reluctance within the industry, and its supply chains, to permit researchers access to documentation and decision makers to allow them to pursue research investigations into modern slavery. Denying access for such research may reflect commercial sensitivities and/or concerns about essentially publicly unspoken corporate concerns about employee recruitment and labour practices within supply chains, and attendant fears of damaging publicity, and possibly criminal prosecution, if modern slavery practices are explicitly revealed. In part the lack of published research on modern slavery within the hospitality industry may also reflect researchers ${ }^{\text {ee }}$ fears for their personal safety if looking to undertake research, in settings where illegal, and criminal activity may be commonplace, and then publish their research findings. Here covert approaches may seem to offer a way forward, but such approaches are unlikely to offer genuine security in an environment where anxiety, suspicion, and the threat of physical violence, may be rife.

Given these thoughts, it is perhaps not surprising that the literature on modern slavery within the hospitality industry has a general, rather than, a specific empirical focus. At the same time, some of the published work has examined modern slavery as one of a number of interlinked issues but has not focused exclusively on modern slavery. In looking to offer some "lessons for tourism and hospitality research", Wen et al. (2020) provided a systematic literature review of human trafficking, which included work on modern slavery. Their work suggested that modern slavery was a global problem, that it was closely tied to migration, and that human trafficking was a primary source of modern slavery. In conclusion the authors called for more research "to examine the dynamics underlying the diverse causes, nature, and consequences of modern slavery" (Wen et al. 2020).

Trasatti and Miller (2019) suggested that hotels were common sites for human trafficking and offered guidance for hospitality employees on reporting and responding to this issue. Trasatti and Miller (2019) also suggested that hotels should provide appropriate training for employees and suppliers and make guests aware of human trafficking hotline telephone numbers, so that they can report any suspicious behaviours. In a similar vein, Paraskevas (2020) examined the various ways in which hotels were vulnerable to modern slavery and explored some of the actions taken by individual hotels to actively oppose modern slavery.

French (2018) argued that the structure and the labour-intensive nature of the UK hospitality industry made it susceptible to labour exploitation and modern slavery. More specifically, French (2018), claimed that the large hotel companies across the UK "have increasingly subcontracted many of the services provided within hotels", and that where hotel managers subcontract the recruitment of staff, they often have little oversight of some of the stages in what may be an extensive labour supply chain. More generally, French (2018) argued that neo-liberal economic globalisation has promoted the casualisation of labour and that such 
"exploitative practices to reduce labour costs can facilitate pathways into modern slavery".

In the light of Rhou and Signale s (2020) argument that the research on the hospitality industry was light on theoretical engagement, it seems appropriate to look to identify potentially useful theoretical frameworks for research into modern slavery. Bales (2006) looked to build a "theory of modern or contemporary slavery through a set of assertions concerning the impact of global demographic and economic change on the nature of the slavery relationship over the past fifty to sixty years". He argued that "since about 1950, the nature of both the packaging of slavery and the way the basic relationship is acted out have been significantly altered by a change in the economic equation of slavery." (Bales 2006). Manzo (2006) proposed an alternative approach to that adopted by Bales, which she classified as being drawn from "Marxian or neo-Marxian political economy." Here the key themes were commodity production and trade, labour costs within a hierarchical division of labour, unequal terms of trade, capitalist expansion vis commodification and economic liberalisation, and the varied and uneven effects of the worldwide expansion of capitalism.

More recently, while Caruana et al. (2020) suggested that modern slavery presented many opportunities for novel theory building, they concluded that existing theories were limited in their ability to conceptualise modern slavery. That said, three sets of theoretical approaches, namely institutional theory, stakeholder theory and contingency theory, merit attention. Flynn and Walker (2020) employed institutional theory, to explore how firms listed on the Financial Times Stock Exchange were responding to modern slavery risks in their supply chains. Here institutional theory was selected because the Flynn and Walker (2020) argued that the transparency provision in the 2015 legislation represented institutional, rather than market, pressure on companies.

In the conclusion to their work on modern slavery in supply chains, Stevenson and Cole (2018) suggested that both stakeholder theory and institutional theory offered potential for future research on modern slavery. Here, Stevenson and Cole (2018), for example, argued that stakeholder theory was valuable in that while the primary audiences for modern slavery statements were external stakeholders, it was important for companies to consider what their modern slavery statements revealed to their suppliers. Gold et al. (2015) argued that research questions about modern slavery could be fruitfully framed by contingency theory and institutional theory. The former was seen to help to achieve a deeper appreciation of the importance of culture, geography, legislation and regulation, while the latter could help in investigations of how, and why, modern slavery traders can continuously resist pressures to adopt more legitimate forms of business.

This literature review of modern slavery in the hospitality industry suggests that the field is currently fragmented, and at a best, embryonic. As such, this mirrors Caruana et al." s (2020) more general suggestion that the field of "modern slavery research in business and management remains significantly, and disappointingly underdeveloped". While the review provides a sense of academic 
context, and some basic reference points for the paper, it does not identify modern slavery in the hospitality industry as distinct field of research, not least in that it lacks an agreed framework, empirically informed research, and a theoretical foundation. Perhaps more importantly in the light of the aims of this paper, the current literature review reveals little research on how large hospitality companies have addressed modern slavery. At the same time, Heyes and Minor (2021) suggested "that hotels are failing to address the risks of modern slavery in their direct operations and supply chains". As such, this highlights a gap in the hospitality literature, but given the role hotel companies, often potentially unwittingly, play in modern slavery, it surely merits attention.

\section{Frame of Reference and Method of Enquiry}

At the outset, the authors would want to emphasise that both the investigation, and the analysis of the information revealed by this investigation, have an explicit qualitative and descriptive focus. With such an approach in mind, the authors chose a simple two step method of enquiry to investigate how the leading hotel companies in the UK had addressed modern slavery statements, but they believe their approach is appropriate in exploratory review. Firstly, the top ten hotel chains in the UK, by the number of rooms, namely Premier Inns, Travel Lodge, Hilton, Holiday Inn, Holiday Inn Express, Double Tree, Britannia Hotels, Ibis, Best Western, and Marriot Hotels, as listed by Statista (2020), provided the initial framework. However, Premier Inns are owned by Whitbread, the Intercontinental Hotel Group (IHG) are the parent company of Holiday Inn and Holiday Inn International, Double Tree is owned by Hilton, and Ibis is part of the Accor Group, so the second stage of the enquiry, which covered eight hotel companies, namely, the Whitbread Group, Travel Lodge, the IHG, Hilton, Britannia Hotels, Accor Group, Best Western, and Marriot Hotels, provided the framework for the second stage of the investigation. This second stage involved a series of Internet searches, using the name of each of the selected hotel companies, and modern slavery statement as the key phrases. These searches, undertaken in April 2021 on the Google search engine, revealed that all but one, namely Best Western, of the selected hotel companies posted a modern slavery statement.

The most recent modern slavery statements from the seven hotel companies provided the empirical material for this paper. As these statements are in the public domain on the hotel companies ${ }^{\text {ee }}$ websites, the authors took the view that they did not need to seek permission to use them. The modern slavery statements were relatively brief and clearly structured, and the authors felt that any form of content analysis would not be necessary. Rather, the authors undertook a close reading of the statements and drew out the important issues and themes. The paper draws extensively on selected quotations drawn from the selected hotel companiese $^{\text {ee }}$ websites. The aim here, was to explore how the hotel companies publicly expressed, and evidenced, their approaches to tackling modern slavery, and the authors were of the opinion that an important way of capturing such 
approaches was to cite the hotel companies ${ }^{\text {ee }}$ own words, not least in that such citations could convey corporate authenticity and offer greater depth of understanding.

\section{Results}

The modern slavery statements posted by the seven selected hotel companies varied in style and content, but rather than looking to describe each statement in detail, the authors looked to identify, and draw out, a number of general themes. More specifically, the authors identified six themes, namely, corporate commitment, risk areas, due diligence, awareness and training, audit, and performance measures. which effectively captured the spirt, if not always the detailed letter of the selected hotel companies ${ }^{\text {ee }}$ approach to modern slavery statements. In practice many of these themes are interlinked, but here they are separately identified to provide a systematic picture of the content of the selected modern slavery statements.

The hotel companies ee corporate commitments were expressed in a variety of ways. Travel Lodge (2020), for example emphasised "we are committed to supporting human rights and to take seriously our responsibilities under the Modern Slavery Act 2015", and "we have a zero tolerance approach to slavery and human trafficking and are dedicated to understanding the risks so that we can work towards ensuring that there is no modern slavery in our business or supply chain". The Accor Group (2020) reported that it was "strongly committed to the goal of being a responsible company that shares value, works to obey ethical principles, complies with applicable laws and regulations, and honours the commitments to its various stakeholders. This commitment extends to human rights including modern slavery and trafficking". While Britannia Hotels (2020) emphasised that the company is "committed to addressing procedures so that compliance with the Slavery Act becomes the normal situation throughout its supply chains", the company also recognised "it will take time to introduce the initiatives".

Marriot Hotels (2020) reported "since 2006, we have had a Human Rights Policy that addresses modern slavery, forced labour and child labour". The IHG (2020) emphasised its commitment "to respecting the human rights of all our colleagues, guests and the communities we operate in", and that "we continue to encourage those we do business with - including our suppliers, owners and franchisees - to prevent, mitigate and address adverse impacts on human rights, including modern slavery". Looking to the future, the IHG (2020) claimed "as an organisation with a long-standing commitment to responsible business, IHG is focused on further developing our approach to human rights and combating modern slavery".

Risk assessments offered some insights into the hotel companies ${ }^{\text {ee }}$ perceptions of the sources of modern slavery and a fairly consistent picture emerged. Whitbread (2020), for example, recognised "there are a number of ways in which 
our business could be affected by modern slavery". The principal risk areas identified by Whitbread were its employees, its supply chain, and its guests. In addressing modern slavery risks, Whitbread argued that having direct control over the recruitment of employees reduced the risk that people working for the company might be victims of modern slavery. Perhaps more pointedly, in focusing on the risk of modern slavery in the supply chain Whitbread (2020) "identified that the majority of risk lies in the lower tiers of our supply chain often a number of tiers away from our direct control". The IHG (2020) identified a number of risk areas, including, its supply chain, third party owners, its own operations, and migrant workers, while Hilton (2020) identified three areas of risk of to modern slavery, namely its own operations, its supply chain, and during the construction of new hotels, and suggested that within these areas, certain groups, namely, migrants, women, and children were particularly vulnerable.

Awareness and training were seen to be important in looking to tackle modern slavery. In outlining its vision, "Action for Positive Hospitality", the Accor Group (2020), for example, stressed it was "committed to increasing awareness of human trafficking and modern slavery at all levels". The IHG (2020) emphasised that "the importance of respecting human rights and combating modern slavery is made clear to colleagues as soon as they start working for IHG through our Code of Conduct training", which "includes information on our approach to human rights and modern slavery and information on how to report concerns". More generally, the IHG also reported that it continued to "leverage important dates such as Anti-Slavery Day (18 October 2020) to raise internal awareness by highlighting the role that hotels can play in combating modern slavery and human trafficking" (IHG 2020).

Whitbread (2020) outlined the company's approach to employee training, which is designed enable them to respond correctly, if they are suspicious about human trafficking and modern slavery activity. Here, Whitbread (2020) reported training all of its team members working across its hotel and restaurant operations. The focus of the company's bespoke training programmes is on "on raising awareness of human trafficking and modern slavery issues, empowering our teams to identify indications of human trafficking abuse in our sites and provide them with the tools to report it quickly and effectively" (Whitbread 2020).

Travel Lodge (2020) stressed "we recognise that awareness amongst our employees is important in preventing modern slavery", and that "this training enables our staff to alert the police to any related issues they identify in the course of their duties". In addressing labour sourcing, Hilton (2020) reported on its approach to training. Here the company stressed that it "continued to roll out our eLearning training on the key risks of modern slavery in labour sourcing". This training is mandatory for all those involved in recruitment and in outsourcing decision making.

Due diligence processes are reported as an important theme in the selected hotel companies ${ }^{\text {ee }}$ modern slavery statements. Hilton (2020) for example, outlined a range of its due diligence processes. In addressing risk monitoring and mitigation, the company suggested that "our mitigation response to identified risks 
depends on Hilton's direct link to the situation and the leverage the company may have in each context" (Hilton 2020). Here Hilton (2020) reported that it encouraged its employees to raise concerns about modern slavery and human trafficking, that there was an anonymous telephone hotline to enable employees to report any such concerns to the company, and that this hotline facility was also available to suppliers, business partners, customers, and members of the public.

Conducting due diligence processes within supply chains was also seen to be an important issue. Marriott Hotels (2020), for example, recognised "the importance of conducting due diligence and responding to concerns raised regarding our supply chains". More specifically, Marriott Hotels (2020) reported on collaborating with its suppliers across three channels of its supply chain, namely furniture, fittings and equipment; operating supplies and equipment; and food and beverages; to encourage them to adopt ethical business standards and human rights compliance measures. In outlining due diligence processes in its supply chain IHG (2020) reported that new suppliers were required to complete a questionnaire, which included information on human rights and the labour environment.

Travel Lodge (2020) reported assessing its "supply chains where there is a risk of slavery and human trafficking taking place (even if this is small), whether from an activity or geographical perspective", and that the company's "central procurement function assists us to have visibility of our suppliers and a better understanding of the risk areas". Further, Travel Lodge (2020) reported that when "taking on new suppliers in areas which we consider to be higher risk, we undertake supplier due diligence and engage with potential suppliers to understand the actions taken by them to reduce the risk of slavery and human trafficking in their supply chains", and that "we include contractual clauses in all our higher risk supplier agreements .....in relation to the monitoring and tackling of slavery".

Some of the seven hotel companies reported commissioning independent audits designed to monitor their suppliers ${ }^{\text {ee }}$ commitments to modern slavery, often as part of their wider approach to human rights. Whitbread (2020), for example, reported working with a third part auditor for suppliers considered to pose high risks. Such audits involve site visits, access to relevant documentation, and interviews with a representative sample of workers. These interviews are undertaken in confidence, in the workers ${ }^{\text {ee }}$ native language, and are seen by the company to provide a safe opportunity for workers to report any concerns or malpractice.

That said, Whitbread (2020) explicitly recognised that that "sometimes workers may feel unable to speak freely when they are in the workplace", and that "in order to ensure we are truly providing the opportunity for honest feedback at all Whitbread PLC audits; we have created a whistleblowing line via our independent auditors who give interviewees a number they can call if they want to speak about anything at a later date". Further, Whitbread (2020) reported that "wherever issues are uncovered through these audits, we work closely with our suppliers to remediate areas of non-compliance to clearly defined and agreed timeframes. This remediation is then verified by a follow up, third party audit to 
ensure compliance. Where our suppliers demonstrate a persistent disregard for working with us to meet the standards outlined in our policy, we reserve the right to cease working with them".

A minority of the selected hotel companies suggested that they were moving towards reporting on their performance, and on identifying key performance indicators, in meeting their commitments to tackling modern slavery. In looking to "measure our performance", the IHG (2020), for example, reported that "as of December 2020, over 2,000 employees had completed its modern slavery training programme and over 4,000 suppliers had signed up to its suppliers code of conduct". Whitbread (2020) identified four "performance indicators", namely, increasing awareness, the sharing of information, partnerships and collaboration, and due diligence in its supply chain. In focusing on due diligence, for example, Whitbread (2020) reported that some $60 \%$ of its "high risk suppliers" had been audited. Travel Lodge (2020) provided a succinct outline of its "key performance indicators", namely, "we would expect that any incident of modern slavery would be a breach of our company policies, contractual terms and/or law", and "we continue to focus on the assessment of our supply chain and high risk areas as well as on ensuring that we do not have any modern slavery in our own business".

\section{Reflections}

The modern slavery statements of the seven selected hotel companies captured their public approach to modern slavery, but some wider issues merit reflection and discussion. The findings reported above suggested that while the hotel companies emphasised their opposition to modern slavery, some of their commitment to tackle what is a complex issue, can be seen as a work in progress. In emphasising their opposition to modern slavery and in reporting on their introduction of measures to monitor and tackle the problem, the selected hotel companies look to reflect UK Government policy, but they face a number of challenges.

Assessing, monitoring and tackling modern slavery within supply chains and recruiting labour, arguably presents two of the biggest challenge for the hotel companies and this challenge is manifest in several ways. Outsourcing is commonplace within the hotel industry, its benefits are seen to reduce costs and increase efficiency, and it can embrace a wide range of functions including the purchasing of furniture, fittings, and operating supplies, equipment maintenance, laundry, and information and communication technology services. Where such outsourcing occurs, then hotel companies effectively have reduced oversight of the workers involved in the sourcing process. At the same time, where hotel companies $^{\text {ee }}$ business models are based around independent ownership, leasing and franchising, rather than direct ownership, then hotel companies are at least one step removed from direct corporate control.

That said, some of the selected hotel companies claimed their approach to modern slavery was effectively underwritten by independent audit. However, 
concerns have been expressed about the efficacy of the audit process in safeguarding against modern slavery. The pressure group Anti-Slavery International (2021) for example, argued that such approaches have their limitations, not least in that "the quality and scope of auditing may be questionable, or there may be practical difficulties such as auditors being unable to speak with workers in their own language".

Anti-Slavery International (2021) also argued that "forced labour is often hidden", that "it is often found in the informal sector, in the early stages of production, often some steps down the supply chain", and that "subcontracting can also hide forced labour as it adds layers between the company and the worker", which "are out of the scope of many audits". Gold et al. (2015) used the term "audit fraud" to describe illegal activities hidden by the supplier from the auditing company. Gold et al. (2015) also suggested that "slave-holders skimming huge profits from their activities will not be susceptible to change in response to premium-price incentives for social standards from the buying company", rather "they might instead take the premium and at the same time extend their existing profitable business model".

Further, Anti-Slavery International (2021) claimed that "even when auditing is of high quality, audits by necessity are merely a snapshot of a particular moment in a particular part of the production system", and that "the auditing mindset tends to be linear and mechanistic and may compartmentalise symptoms, preventing observers from seeing the whole complex picture which might together constitute forced labour". More positively, Benstead et al. (2020) argued that "a targeted audit", which investigates "the end-to-end recruitment process by using a parallel structure of management and worker interviews and documentation review", is "more likely to reveal key indicators of modern slavery".

The concept of the modern slavery statement has attracted a number of criticisms. New and Hsin (2021), for example, argued that while modern slavery statements "present interesting information about the management of working conditions in the firms ${ }^{\text {ee }}$ supply chains, they do little to address the problems of modern slavery per se". Simic and Blitz (2019) argued that modern slavery statements are "often perfunctory and are used to satisfy international agendas and country commitments, or to enhance the perception of the country and its position in the global outsourcing business". Simic and Blitz (2019) also argued that the capacity of modern slavery statements "is often limited, especially as it regards remedying risks", and that "the quality, scope, depth, and regularity of reports are frequently compromised, especially since there are no meaningful sanctions for non-compliance".

There have also been issues about the ambivalent role of the media in publicising modern slavery statements. Simic and Blitz (2019), for example, argued that on the one hand "companies' over-reliance on media exposure of transparency statements has been instrumentalised by the state which has paid lip service to proper law enforcement mechanisms". On the other hand, Simic and Blitz (2019) also suggested "the possibility of unsolicited media publicity may 
often act as a deterrent for businesses and could push them in the opposite direction: it can enhance non-compliance or highly restrained compliance".

More generally, in recent years the hospitality industry, and more specifically many large hotel companies, have taken an increasing interest in corporate social responsibility, and there are issues about where modern slavery sits within corporate social responsibility policies. New (2015), for example, looked to examine how modern slavery within supply chains challenged conventional thinking and practice on corporate social responsibility. More specifically, New (2015) pointed out "the potential differences between modern slavery and other corporate social responsibility issues "e and highlighted "the paradox that firms' approaches to the issue may run in parallel with actions that foster the problem in the first place".

Many hotel companies publish corporate social responsibility reports, but their coverage of modern slavery in such reports has often been limited. Jason Nunn, Whitbread's Director of Business Engagement Whitbread (2021) for example, simply asserted that the company had "demonstrated their commitment to preventing modern slavery" but offered no evidence within the report to support this assertion. Neither Travel Lodge, nor Britannia Hotels, posted a corporate social responsibility report. However, the larger international hotel companies did publish outline information on their approach to modern slavery in their corporate sustainability reports. Hilton (2019), for example, published information on how the company used its corporate responsibility management platform to measure modern slavery risks, and provided some outlines of its approach to training and to due diligence in its supply chain, in its corporate social responsibility report, though there was no detailed independent assurance of this information.

Finally, and more critically, there are fundamental questions about the effectiveness of modern slavery statements in tackling, and ideally eradicating, modern slavery, not least because Monciardini et al. (2021) suggested that within the UK noncompliance with the 2015 legislation "is a common occurrence". At the same time, Bannerjee (2020), argued that corporate social responsibility, codes of conduct and multi-stakeholder initiatives will not "address the real problem of modern slavery", and claimed that "most corporations do very little apart from issuing public statements and commitments to eradicate forced labour". Indeed, Banerjee (2020) argued that the current initiatives to "give the appearance that firms and suppliers are working to address the problems with little evidence of outcomes".

\section{Discussion, Limitations and Future Research}

This review of modern slavery statements published by the seven selected hotel companies has some implications for the theoretical approaches mentioned earlier. On the one hand, the review of the selected companies ${ }^{\text {ee }}$ modern slavery statements provided little insights into the theories proposed by Bales (2006) and Manzo (2006). On the other hand, the review suggested that the seven hotel 
companies publicised their concerns about modern slavery and responded positively to UK government pressure and legislation to introduce modern slavery statements. As such, the selected hotel companies ${ }^{\text {ee }}$ approach can be seen to be consistent with institutional theory. At the same time, the findings revealed that while the hotel companies emphasised their commitment to tackle modern slavery, and outlined their approach to awareness and training, and to due diligence, their enthusiasm for independent auditing, and for identifying, and reporting on, performance measures was more limited. This, in turn suggests that institutional theory does not tell the full story in conceptualising corporate approaches to modern slavery.

In highlighting the role and importance of a number of stakeholders, including suppliers, employees, customers, and government, in identifying and developing awareness of modern slavery within the selected hotel companies, stakeholder theory might be seen to be useful in informing how the selected hotel companies have developed their modern slavery statements. However, stakeholder theory is generally seen to be based on, and around, open relationships, trust and shared goals, and these qualities are certainly not common to all the stakeholders involved in modern slavery. Contingency theory helps to shed some light on how the selected hotel companies approached modern slavery, but perhaps only in so far as it signals that many of the characteristics of the hotel industry, and the wider hospitality industry, seem to make them susceptible to modern slavery. More widely, the paper has provided an opportunity to add to the hospitality industry's engagement with theory.

The paper has a number of potential corporate, managerial, and operational implications for the hotel industry. Some of the selected hotel companies reported commissioning independent audits in an attempt to safeguard against modern slavery in their supply chains, but they may be advised to strengthen the quality and scope of their audit processes. At the same time, hotel companies may also look to include both greater, and more explicit commitment to, and treatment of, of modern slavery within their corporate responsibility strategies and attendant reporting and external assurance processes. Pursuing both of these measures will generate new costs for hotel companies but it will help to increase the transparency and public accountability of their campaigns against modern slavery.

At the operational and managerial level, the often high turnover of employees within the hotel industry can be seen to necessitate an ongoing managerial focus on the use of agency workforces and the subcontracting of labour supplies. While some decisions about the recruitment of employees may be taken at the corporate level, maintaining regular managerial relationships and contacts, where possible at the local level, will also be important. A continuing, and arguably enhanced, commitment to awareness training would also seem to be important in maintain the focus on modern slavery at the operational level. Given the illegal, and secretive nature, of modern slavery, bringing managers, and employees, into closer, and more regular, contact with individuals and organisations suspected of being engaged in modern slavery, and enhancing employee and customer awareness of such activity, may pose personal dangers for both employees and 
customers. Even with support from law enforcement agencies, there are no simple solutions to these problems, and it is important that they are fully recognised at the corporate, managerial and operational levels.

The paper has a number of limitations. In looking to review the modern slavery statements of seven leading hotel companies in the UK, it provided a limited perspective on modern slavery within the hotel industry. The empirical material for the review is drawn exclusively from the corporate websites of the selected hotel companies, at a set point in time, and does not include any primary information supplied by the hotels' executives, managers or employees, or any information obtained from the hotels ${ }^{\text {ee }}$ suppliers, or from employment agencies. However, the authors believe this approach is appropriate in what is an explanatory review paper, and that the paper makes a small contribution to what is a currently a noticeable gap in the hospitality literature, and that it may provide a platform for future research into modern slavery in the industry.

However, while modern slavery within the hotel industry, and more widely within the hospitality industry, offers a potentially rich variety of research opportunities, it is important to recognise that it a very challenging research arena. While slavery is illegal in the vast majority of jurisdictions, it can also be a lucrative economic activity, and those individuals and organisations involved in modern slavery, human trafficking and bonded labour, will generally do all they can to hide, and maintain the secrecy of, their activities. Researchers who look to conduct primary research into modern slavery activities may be placing themselves, possibly their research colleagues, and those who participate in such research, in serious personal danger. Problems, and tactics designed to minimise such problems, are rarely addressed in the research literature but they may curtail many potentially promising modern slavery research agendas. At the same time, researchers may face a range of ethical issues, not least researchers ${ }^{\text {ee }}$ responsibility to those who participate in their research. More generally, there are some guidelines for social science researchers looking to pursue hidden activities (e.g. Ellard-Gray et al. 2015), but researching modern slavery within the hospitality industry seems fraught with difficulties and dangers.

That said, in their study of responses to Australia's modern slavery legislation, Christ and Burritt (2018) outlined a number of future research directions in corporate modern slavery, and here the focus was on employee representatives and governments and their representatives. Looking to future research agendas, on the one hand, the current authors would recommend a more detailed and wide-ranging empirically based research enquiry into the impact of hotel companiese modern slavery statements on modern slavery within their operations. On the other hand, a number of more general research opportunities into corporate approaches to modern slavery within the hospitality industry can be identified. Here, research investigations might profitably explore the ways in which global hospitality companies address the issue of modern slavery. Such work could include large scale questionnaire surveys of, as well as personal interviews and focus group meetings, with, senior hospitality company executives to learn how a range of hospitality companies have developed, and continually 
look to strengthen, their policies on modern slavery. Such research agendas may also explore if, and how, employees, customers, suppliers, governments, and law enforcement agencies are involved in the policy development process. In addition, such research into modern slavery within the hospitality industry may help to both test, and illuminate, theoretical approaches to modern slavery, and perhaps more importantly, help to answer the call by Gold et al. (2015) for new theory development to facilitate the understanding of modern slavery.

\section{References}

Accor Group (2020) Slavery and human trafficking statement. Accor Group.

Allain J, Bales K. (2012) Slavery and its definition. Global Dialogue 14(2): 1-8.

Anti-Slavery International (2021) What is modern slavery? Anti-Slavery International.

Bales K (2006) Testing a theory of modern slavery. Retrieved from: https://documenta tion.lastradainternational.org/lsidocs/bales test theory 0607.pdf. [Accessed 24 May 2021]

Bales K, Hesketh O, Silverman B (2015) Modern slavery in the UK: how many victims. Significance 12(3): 16-21.

Banerjee B (2020) Modern slavery is an enabling condition of global neoliberal capitalism commentary on modern slavery in business. Business and Society 60(2): 415-419.

Benstead AV, Hendry LC, Stevenson M (2020) Detecting and remediating modern slavery in supply chains: a targeted audit approach. Production Planning and Control (Jul).

Britannia Hotels (2020) Slavery act statement. Britannia Hotels.

Caruana R, Crane A, Gold S, LeBaron G (2020) Modern slavery in business: the sad and sorry state of a non-field. Business in Society 60(2): 251-287.

Christ KL, Burritt RL (2018) Current perceptions on the problem of modern slavery in business. Business Strategy and Development 1(2): 103-114.

CMS Law (2019) Modern slavery - A key issue for the hospitality sector. CMS Law.

Ellard-Gray A, Jeffrey NK, Choubak M, Crann SE (2015) Finding the hidden participant: solutions for recruiting hidden, hard-to-reach, and vulnerable populations. International Journal of Qualitative Methods 14(5): 1-10.

Flynn A, Walker H (2020) Corporate responses to modern slavery: an institutional theory perspective. European Business Review 3(2): 295-315.

French S (2018) Between globalisation and Brexit: migration, pay and the road to modern slavery in the UK hospitality industry. Research in Hospitality Management 8(1): 23-31.

Gold S, Trautrims A, Trodd Z (2015) Modern slavery challenges to supply chain management. Supply Chain Management 20(5): 485-494.

Heyes A, Minor K (2021) Luxury hospitality - Is this time to rethink the ethical stance? Research in Hospitality Management 11(1): 5-7.

Hilton (2019) Travel with purpose; Hilton 2019 corporate social responsibility report. Hilton.

Hilton (2020) Human slavery and trafficking statement. Hilton.

Human Trafficking Foundation (2018) Tackling modern slavery in the hotel sector. Human Trafficking Foundation. 
IHG (2020) Modern Slavery Statement 2020. IHG.

International Labour Office (2014) Profits and poverty: the economics of forced labour. International Labour Office.

International Labour Office (2017) Global estimates of modern slavery: forced labour and forced marriage. International Labour Office.

Landman N, Silverman BW (2019) Globalization and modern slavery. Politics and Governance 7(4): 275-290.

Manzo K (2006) Modern slavery, global capitalism and the deproletarianisation in West Africa. Review of African Political Economy 32(106): 521-534.

Marriott Hotels (2020) UK human trafficking transparency statement. Marriott Hotels.

Mende J (2019) The concept of modern slavery: definition, critique, and the human rights frame. Human Rights Review 20(2): 229-248.

Monciardini D, Bernaz N, Androv A (2021) The organizational dynamics of compliance with the UK modern slavery act in the food and tobacco sector. Business and Society 60(2): 288-340.

New SJ (2015) Modern slavery and the supply chain: the limits of corporate social responsibility? Supply Chain Management 20(6): 697-707.

New S, Hsin L (2021) Deconstructing modern slavery statements: a detailed analysis of Arcadia Group and Babcock International. SSRN (Jan).

Paraskevas A (2020) Human trafficking and modern slavery in Europe"s hotels. In C Lashley (ed.), chapter 5. Slavery and Liberation in Hotels Restaurants and Bars. Oxford: Routledge.

Rhou Y, Signal M (2020) A review of the business case for CSR in the hospitality industry. International Journal of Hospitality Management 84(Jan): 102330.

Robinson RNS (2013) Darker still: present-day slavery in tourism and hospitality services. Hospitality and Society 3(2): 93-11.

Simic A, Blitz BK (2019) The modern slavery regime: a critical evaluation. Journal of the British Academy 7(1): 1-34.

Statista (2020) Leading hotel chain brands in United Kingdom (UK) 2018 by number of rooms. Statista.

Stevenson M, Cole R (2018) Modern slavery in supply chains: a secondary data analysis of detection, remediation and disclosure. Supply Chain Management 12(3): 81-99.

Trasatti MA, Miller ZA (2019) Human trafficking: how businesses can work to combat the modern slavery epidemic. Risk Management 6(8): 20-25.

Travel Lodge (2020) Modern slavery act statement 2020. Travel Lodge.

United Nations Office of the High Commissioner Human Rights (2021) Slavery convention. United Nations Office of the High Commissioner Human Rights.

Unseen (2021) Spot the signs of modern slavery. Unseen.

Wen J, Klarin A, Goh E, Aston J (2020) A systematic review of the sex-trafficking literature for tourism and hospitality research. Journal of Hospitality and Tourism Management 45(Dec): 370-376.

Whitbread (2020) Whitbread modern slavery statement 2019/2020. Retrieved from: https://cdn.whitbread.co.uk/media/2021/02/02103453/whitbread-modernslaverystatement-2019-20.pdf. [Accessed 3 April 2021]

Whitbread (2021) Making a positive difference. Retrieved from: https://cdn. Whitbread. co.uk/media/2021/02/23234132/Whitbread-Environmental-Social-andGovernanceReport-202021-1-compressed.pdf. [Accessed 8 April 2021] 